H. Ding, P. L. Deroy, C. PerReault, A. LARivée, A. Siddiqui, C. G. CAldwell, S. HARRAN, P. G. HARRAN* (UNIVERSITY OF CALIFORNIA, LOS ANGELES AND JOYANT PHARMACEUTICALS, DAllas, USA; PARAZA PHARMA, MONTRÉAL, CANADA) Electrolytic Macrocyclizations: Scalable Synthesis of a Diazonamide-Based Drug Development Candidate Angew. Chem. Int. Ed. 2015, 54, 4818-4822.

\title{
Synthesis of DZ-2384
}

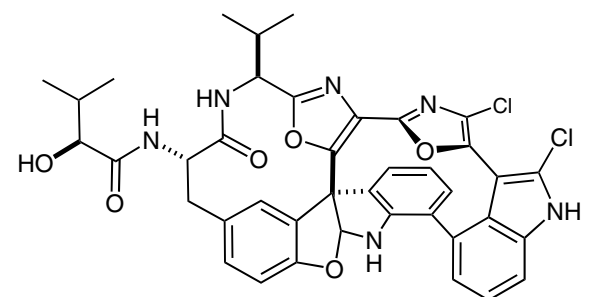

Diazonamide A

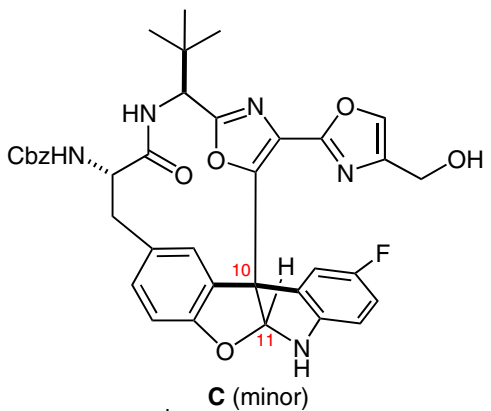<smiles>CC(C)(C)C(NC(=O)[C@H](Cc1ccc(O)cc1)NC(=O)[O-])c1nc(-c2nc(CO)co2)c(-c2c[nH]c3ccc(F)cc23)o1</smiles>

A

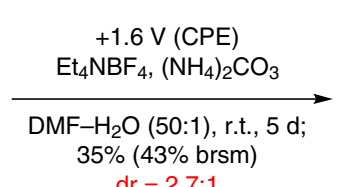

$$
\begin{aligned}
& d r=2.7: 1
\end{aligned}
$$

\section{Gategory}

Synthesis of Natural

Products and

Potential Drugs

\section{Key words}

\section{DZ-2384}

diazonamide A

macrocyclization

anodic oxidation

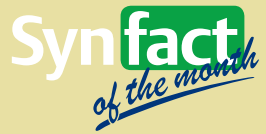

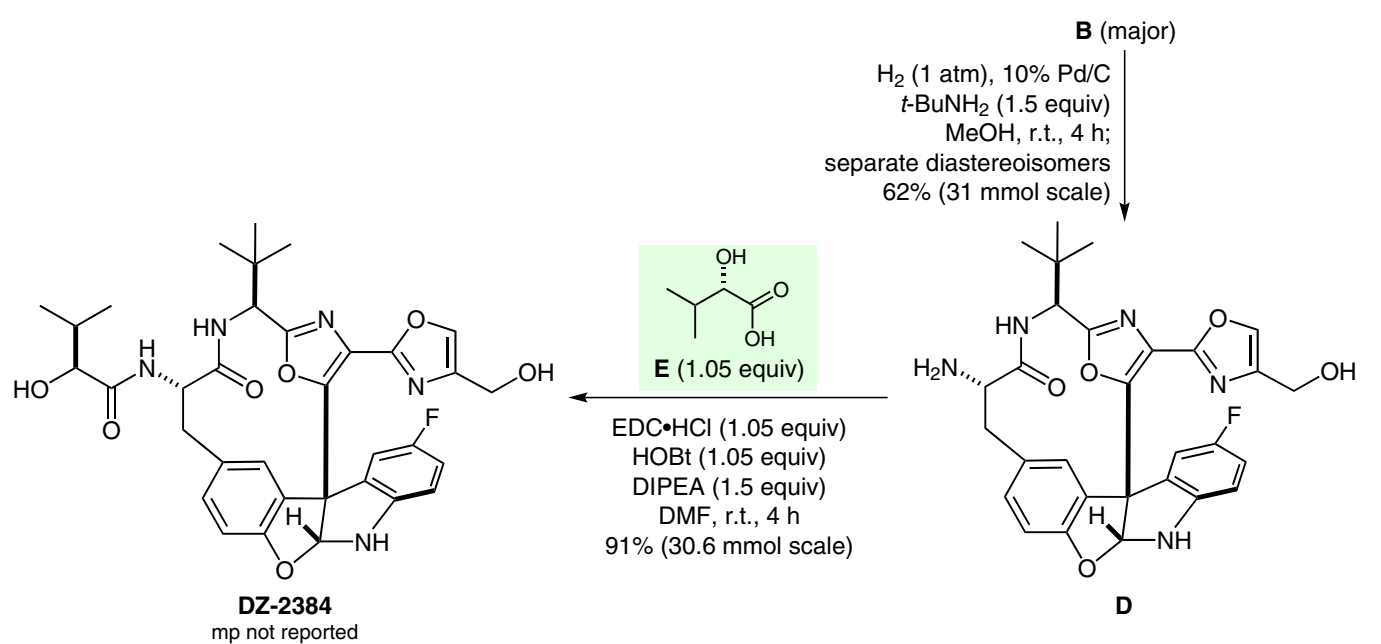

Significance: Diazonamide A, a metabolite of the ascidian Diazona angulata, displays potent in vitro activity against human colon cancer. DZ-2384 is a truncated analogue of diazonamide $A$ that is 10 to 50-fold more efficacious than diazonamide $A$ as an anti-mitotic agent in rodents. The synthesis of DZ-2384 proceeded in 13 total operations and $5.7 \%$ overall yield from L-tert-leucine.

SYNFACTS Contributors: Philip Kocienski

Synfacts 2015, 11(7), 0681 Published online: 17.06.2015 Dol: 10.1055/s-0034-1380900; Reg-No.: K02915SF
Comment: The key step of the synthesis depicted is a macrocyclization initiated by an anodic oxidation of $\mathbf{A}$ at a graphite surface. Anodic oxidation of 60 grams of $\mathbf{A}$ gave 21 grams of a mixture of $\mathbf{B}$ (major) and its epi-C10,C11 diastereoisomer C (minor, $d r=2.7: 1$ ), which was separated from unreacted $\mathbf{A}(11.0 \mathrm{~g})$ by silica gel chromatography. Separation of the diastereoisomers was achieved after hydrogenolysis of the Cbz group. 